\title{
Training Students Through a Community Outreach Program to Support Families of Children with Autism Spectrum Disorder
}

\author{
Joann P. Benigno` \\ Ohio University, benigno@ohio.edu \\ John W. McCarthy \\ Ohio University, mccarthj@ohio.edu \\ Sarah O. Taylor \\ Ohio University, taylors@ohio.edu
}

See next page for additional authors

DOI: https://doi.org/10.30707/TLCSD3.1Benigno

Follow this and additional works at: https://ir.library.illinoisstate.edu/tlcsd

Part of the Scholarship of Teaching and Learning Commons, and the Speech Pathology and Audiology Commons

\section{Recommended Citation}

Benigno', Joann P.; McCarthy, John W.; Taylor, Sarah O.; Gornichec Wright, Bridget; and Lee, Chao-Yang (2019) "Training Students Through a Community Outreach Program to Support Families of Children with Autism Spectrum Disorder," Teaching and Learning in Communication Sciences \& Disorders: Vol. 3: Iss. 1, Article 5.

DOI: https://doi.org/10.30707/TLCSD3.1Benigno

Available at: https://ir.library.illinoisstate.edu/tlcsd/vol3/iss1/5

This Scholarship of Teaching and Learning Research is brought to you for free and open access by ISU ReD: Research and eData. It has been accepted for inclusion in Teaching and Learning in Communication Sciences \& Disorders by an authorized editor of ISU ReD: Research and eData. For more information, please contact ISUReD@ilstu.edu. 


\title{
Training Students Through a Community Outreach Program to Support Families of Children with Autism Spectrum Disorder
}

\begin{abstract}
This outreach program involved training eight graduate and 19 undergraduate students to create evidence-based communication supports for families of children with autism spectrum disorder (ASD) within the context of a two-course sequence on ASD. During the training program, ten families in rural Appalachia benefited from our services. Student and family satisfaction data with the outreach program was highly positive. Undergraduate and graduate university students participating in the program met or partially met $97 \%$ of their goals set at the beginning of each semester. Undergraduate students' selfratings of their own knowledge about material covered in the course were significantly higher than their confidence in applying their knowledge about the materials. Thematic analyses of students' comments about their experiences revealed that the hands-on experience and opportunities to create materials and collaborate with each other were among the aspects of the program they liked most. The value of outreach programs to foster training of undergraduate and graduate students through community connections will be discussed.
\end{abstract}

\section{Keywords}

Autism Spectrum Disorder, training, students, community outreach

\section{Cover Page Footnote}

We would like to recognize the OHIO University 1804 Fund for supporting the work presented in this manuscript as well as the graduate and undergraduate participants and families who participated in the outreach program.

\section{Authors}

Joann P. Benigno`, John W. McCarthy, Sarah O. Taylor, Bridget Gornichec Wright, and Chao-Yang Lee 
There is an undeniable need to provide support for families of individuals with disabilities, including autism spectrum disorder (ASD). However, service delivery in the schools, private practice, or other settings may not adequately meet the needs of children with ASD and their families. According to caregivers of children with ASD, services in general as well as access to parent and professional networks are limited (Auert, Trembath, Arciuli, \& Thomas, 2012; Finke, Drager, \& Serpentine, 2015; Vohra, Madhavan, Sambamoorthi, \& St. Peter, 2014) and the evidence base of outreach programs for families of individuals with disabilities is still emerging. In regions of the country where services are less accessible, outreach is even more critical.

One avenue for providing support for families of children with ASD is through the creation of communication aids. As indicated in the evidence-based practice guidelines for ASD, the American Speech-Language-Hearing Association (ASHA) suggests that tools such as charts, visual schedules, reminders, communication boards, picture exchange communication systems, maps, Social Stories ${ }^{\mathrm{TM}}$ (Gray, 2015), and other types of visual organizers are helpful for children with ASD (ASHA, n.d.). Though these materials must be individualized in order to be most effective (Rao \& Gagie, 2006), healthcare professionals and caregivers of children with ASD are already taxed to their limits and may not have the time required to create customized materials on a regular basis (Serpentine, Tarnai, Drager, \& Finke, 2011). To this end, we developed our outreach program to meet the needs of families of children with ASD in an underserved area while simultaneously training future professionals to create individualized, evidence-based materials for children with ASD.

\section{Personnel Preparation in Autism Spectrum Disorder}

Personnel preparation in the area of ASD is vital and future professionals in speech-language pathology (SLP) need to develop the knowledge and skills integral to identifying, treating, and advocating for the needs of individuals with ASD. Among SLPs working in health care facilities, approximately $16.4 \%$ of their caseload involves treatment of children with ASD (ASHA, 2015) and $91.3 \%$ of school-based SLPs report that they work with children with ASD on a regular basis (ASHA, 2016). The reported knowledge base, skill set, and confidence in working with children with ASD may be limited, even among certified SLPs, but factors such as experience in the field can increase clinicians' confidence in working with this population (Cascella \& Colella, 2004; Plumb \& Plexico, 2013; Schwartz \& Drager, 2008). The pattern is similar among related professionals in education (Williams, Schroeder, Carvalho, \& Cervantes, 2011) and music therapy (Gadberry, 2011).

\section{Student Preparation: Academic and Clinical Experiences}

Relatedly, the academic and clinical preparation of undergraduate and graduate students who will likely provide healthcare services to individuals with ASD in their future careers is of great importance. In a survey study involving 252 undergraduate students studying healthcare professions, Freedman (2014) examined the students' knowledge of ASD relative to the following factors: academic status (e.g., sophomore, junior), experiences with individuals with ASD, relevant academic coursework, and desire to provide services to individuals with ASD in the future. Areas of inquiry addressed in the survey included general ASD knowledge, myths, traits, and treatments. Across all participants, $40.1 \%$ reported that they had gained no knowledge of ASD in their 
coursework and 51.2\% reported little exposure. On average, students' accuracy on the knowledge portion of the survey was $68.3 \%$. Although academic status did have an impact on how accurately the students answered the questions, students who had more personal experiences with individuals with ASD, a greater amount of ASD coverage in their coursework, and a desire to provide services to individuals with ASD in the future answered a higher percentage of the knowledge questions correctly. These findings reflect the importance of providing students with adequate experience and coursework to increase their overall knowledge of ASD.

Although continuing education courses during one's professional career can facilitate further growth and understanding of specific disorders such as ASD, connections between knowledge and practice need to be made early in career development to increase future professionals' ease and understanding in working with children with ASD. Future SLPs will need to be equipped with the knowledge and skills necessary to work both collaboratively and independently within their scope of practice. Research by Howell, Wittman, and Bundy (2012) on collaborative clinical training experiences of graduate clinicians in the fields of occupational therapy and psychology suggests that students recognize the benefits associated with collaborative training opportunities. Learning about themselves and learning to appreciate professional differences were among the themes discussed by students who co-treated a child with ASD.

Specific to training students studying Communication Sciences and Disorders (CSD) in the provision of services to children with ASD, a study by Donaldson (2015) included two SLP graduate students who provided evidence-based therapy services to a child with ASD and their sibling with supervisor mentorship. At the outset of the experience, students completed clinical observations, coursework, and knowledge assessments to build foundational knowledge in ASD as well as specific treatment methods they would implement in therapy. The ten-week training program included routine meetings with their supervisor, self-reflection exercises, and enrollment in a related seminar. By the end of the program, students were able to organize and implement therapy independently. Such experiences in providing services to children with ASD will allow future healthcare providers to gain knowledge and skills that will be necessary in optimally serving children with ASD and their families.

Taken together, these findings underscore the necessity of designing effective outreach programming to address the needs of both children with ASD and their families while training future professionals who will provide services to these children. We describe a training model centered on ASD that includes the simultaneous training of graduate and undergraduate students during two semester courses with an embedded outreach component geared toward families who have children with ASD. Given the location of the university, the training program allowed us to target families in a significantly underserved region of the country.

\section{The Present Study}

The goals of this program were two-fold: (1) to develop an outreach program for families who have children with ASD and (2) to establish a training model for undergraduate and graduate students in CSD and in other related disciplines. The outreach program offered students a realistic representation of providing services to children with ASD and their families (e.g., interviewing parents and incorporating their input into the products, assessment, trial and error in the creation 
of individualized communication supports, and collaboration with individuals from other fields). Ideally, the goal was that the skills fostered would carry over into graduate training and professional clinical experiences.

Students learned how to design visual supports tailored to the individual child's interests and communication status. Examples included Social Stories ${ }^{\mathrm{TM}}$ (Gray, 2015), visual schedules, choice boards, and 5-Point Scales (Dunn Buron \& Curtis, 2012). Since these supports are often relied upon by the general population of children with ASD (Schlosser et al., 2016), it is important that students become equipped with the knowledge of current evidence-based practices. Because caregivers and other professionals have limited time and resources to create customized materials (Serpentine et al., 2011; Jonsson, Kristoffersson, Ferm, \& Thunberg, 2011), we predicted that the outreach component would not only save families time, but would also provide them with a set of functional, effective materials to support schedules and routines at home.

\section{Method}

\section{Participants.}

Student Participants. The program took place over two academic years and involved training one cohort of students each year. Across both cohorts, participants included eight MA-SLP (all female) graduate students and 19 undergraduate students (18 female; 16 majors in CSD, two from Music Therapy and one from Psychology). Due to the timing of the receipt of funding, undergraduate students were selected by the faculty mentors associated with the program. During the second year, there was an application process for the undergraduate students and students within and outside of CSD were invited to apply. Students were chosen based on academic merit, a letter of recommendation, their resume, statement of interest, relevant experience, and ability to commit to the two-semester program. Faculty and advisors in Education, Music Therapy, and Psychology forwarded the program announcement to students. During both years, graduate students were selected based on strong clinical interests and experience in the area of ASD as indicated in their application for graduate school. Graduate students received compensation (not course credit) for participating in the class and mentoring the undergraduate students. Undergraduates earned three credits per semester (six credits total) and were graded on assignments, exams, presentations, and contributions to group projects and outreach activities.

Families. Ten families who have a child with ASD participated (one female child). The average age of the children was 7.38 years (range $=3.83-14.83$ years). All families resided in an underserved region of a state in the Midwest and had a child with a confirmed diagnosis of ASD, per parent report.

\section{Procedures.}

Student Procedures. All students completed a two-semester course sequence on ASD. Core topics of both courses included relative challenges and strengths representative of children with ASD and creating the evidence-based communication supports. Students learned how to create visual schedules, choice boards, Social Stories ${ }^{\mathrm{TM}}$ (Gray, 2015), 5-Point Scales (Dunn Buron \& Curtis, 2012), and additional materials requested by families. Student activities included a fall semester case project, research article discussions and presentations, and a series of critical thinking papers on research articles and clinical issues. Graduate students served as mentors to the undergraduates 
for presentations, projects, and family outreach activities with support from the faculty and clinical supervisor affiliated with the project. In addition, guest lectures were delivered by professionals in occupational and physical therapy, music therapy, social work, and a parent of a child with autism. See Table 1 for a list of course topics and activities by semester. At the end of each semester, all students completed a survey about their experiences (see Appendices A and B). Note that the completion of these surveys was voluntary; all students completed an informed consent and this study was approved through the Institutional Review Board at our university.

Table 1

Representative Course Topics and Activities for Fall and Spring Semesters

\begin{tabular}{|c|c|c|}
\hline & Representative Topics & Core Activities \\
\hline $\begin{array}{l}\text { Fall } \\
\text { semester }\end{array}$ & $\begin{array}{l}\text { Overview of ASD and DSM-V Criteria } \\
\text { Joint attention and theory of mind } \\
\text { Executive function } \\
\text { Routines and visual supports } \\
\text { Functional Communication Profile } \\
\text { Introduction to augmentative and } \\
\text { alternative communication }\end{array}$ & $\begin{array}{l}\text { Research articles and supplementary readings } \\
\text { Research article presentations } \\
\text { Critical thinking papers } \\
\text { Guest speakers } \\
\text { Workshops on creating visual supports } \\
\text { Case study project }\end{array}$ \\
\hline $\begin{array}{l}\text { Spring } \\
\text { semester }\end{array}$ & $\begin{array}{l}\text { Introduction to current evidence-based } \\
\text { treatment approaches } \\
\text { Treatment in the schools } \\
\text { Augmentative and Alternative } \\
\text { Communication Profile } \\
\text { Caregivers of children with ASD }\end{array}$ & $\begin{array}{l}\text { Research articles and supplementary readings } \\
\text { Research article presentations } \\
\text { Critical thinking papers } \\
\text { Guest speakers } \\
\text { Review of visual supports } \\
\text { Outreach to families }\end{array}$ \\
\hline
\end{tabular}

Note. ASD = autism spectrum disorder; DSM-V = Diagnostic and Statistical Manual of Mental Disorders, Fifth Edition.

Family Outreach Procedures. Following a phone screen to determine eligibility and interest, families participated in two sessions. During Session 1, two MA-SLP students used the Functional Communication Profile-R (Kleiman, 2003) or the Augmentative and Alternative Communication Profile (Kovach, 2009), as appropriate, to assess the child's communication strengths and challenges. After the consent and assent process, the child remained in the room with the two MASLP students. The session was videotaped to allow for review and confirmation of the behaviors observed and the activities the children participated in during the session. On average, these sessions lasted 50 minutes $(S D=9.82$ minutes; range $=37.5-61.72$ minutes). Types of activities 
varied depending on the age of the child; however, the majority of activities involved games (24.6\%; e.g., board games), toys and manipulative toy play sets $(21.3 \%$; e.g., farm animals, blocks), and "getting to know you" conversation-based activities (14.75\%; e.g., developmentally appropriate games adapted to incorporate conversational topics).

In an adjacent room with a two-way mirror that allowed for observation, the primary investigator (first author) interviewed the accompanying caregiver(s) regarding the child's strengths, challenges, and current communication supports used at home and school. Caregivers were also asked to provide input on needed materials and customizations (e.g., color scheme, items for card sets, child's interests). During Session 2, which occurred within two to three weeks of Session 1, the caregiver(s) and child received the materials and the MA-SLP students described how to implement the materials at home. All caregivers received instructions for each of the material sets created. Within one to two weeks of Session 2, the first author conducted the caregiver satisfaction survey via phone. The survey was composed of twelve statements regarding satisfaction with the program and materials; caregivers were asked to rate their agreement with statements on a scale of one to five (five being strongly agree). Caregivers were also asked to provide any additional comments on the program and the materials they received. The complete workflow model detailing student and supervisor responsibilities from the screening through the satisfaction survey is located in Table 2. This workflow model was used to keep all team members on track with respect to timely, quality creation and distribution of materials to families.

University Students' Goals and Survey Data. All students set three goals at the beginning of each semester that they wanted to achieve. At the end of each semester, they completed a survey that included questions on their knowledge and confidence in applying course material learned and whether they met, partially met, or did not meet their goals. The survey included a combination of open-ended questions, rating measures (i.e., 1-5 Likert scales), and space for students to provide comments about their ratings. In the first section of the survey, students were asked two openended questions about what they liked most and least about the experience. In the second section, they evaluated the goals set at the beginning of the semester. In section three, students rated their knowledge of and confidence in applying course content. Section four required students to rate perceptions of their own skills (critical thinking, written and oral communication, and collaborative ability) from the beginning to the end of the term. Students took approximately 45 minutes to complete the surveys.

Table 2

Workflow Model for Family Outreach

\begin{tabular}{|l|l|}
\hline Step 1 & Initial phone screen and scheduling of the first session. \\
\hline Step 2 & First session with family completed in the university clinic. \\
\hline Step 3 & $\begin{array}{l}\text { MA-SLPs and undergraduates review video recording of first session, caregiver } \\
\text { interview, and assessment forms within three business days of the first session. }\end{array}$ \\
\hline Step 4 & $\begin{array}{l}\text { MA-SLPs and undergraduates generate list of materials for the child based on } \\
\text { information gained during the first session within one week. }\end{array}$ \\
\hline
\end{tabular}




\begin{tabular}{|l|l|}
\hline Step 5 & Follow-up phone call/email to caregiver to discuss materials and address questions. \\
\hline Step 6 & $\begin{array}{l}\text { MA-SLPs and undergraduates submit drafts of materials to faculty advisor and } \\
\text { clinical supervisor for input within two weeks of the first session. MA-SLPs } \\
\text { provide feedback throughout. }\end{array}$ \\
\hline Step 7 & $\begin{array}{l}\text { Faculty advisor and clinical supervisor provide feedback on drafted materials } \\
\text { within two business days. }\end{array}$ \\
\hline Step 8 & $\begin{array}{l}\text { MA-SLPs and undergraduates create final drafts of materials within three weeks } \\
\text { of the first session. }\end{array}$ \\
\hline Step 9 & $\begin{array}{l}\text { Contact family to schedule follow-up session. MA-SLPs and faculty advisor } \\
\text { present materials to the child and their caregiver(s). }\end{array}$ \\
\hline Step 10 & $\begin{array}{l}\text { Faculty advisor follows-up with caregiver and administers satisfaction survey } \\
\text { within 1-2 weeks of receipt of materials. }\end{array}$ \\
\hline
\end{tabular}

\section{Results}

The family data results are presented first, followed by the university students' results. Themes from qualitative comments made by caregivers and students are included in each section.

Family Data. Across the ten families who participated in the program, approximately 120 individualized materials and material sets were created. On average, each family received 13 materials and material sets (range $=3-26$ materials). Approximately $79 \%$ of those materials included visual schedules, icon sets, Social Stories ${ }^{\mathrm{TM}}$ (Gray, 2015), and 5-point scales (Dunn Buron \& Curtis, 2012). Depending on the needs of the child and the family, additional resources that could be of further assistance were provided (e.g., helpful websites and links to items the family could purchase). On average, caregivers' composite satisfaction ratings $(n=8)$ were very positive $(M=4.89$ out of $5, S D=.11)$. Several parents noted the importance of a program like this in an underserved region. Parents also discussed the quality of the materials and the professionalism shown by the students who worked with their child. All caregivers who provided feedback expressed that the needs of their child and family were met.

\section{Student Data.}

Goals. Recall that each student set three goals for themselves at the beginning of each semester. Across both cohorts of the training program, $97.44 \%$ of undergraduate and MA-SLP students' goals were met or partially met. Student goals were classified into one of the following themes: outreach (e.g., creating materials and working with families; $27.16 \%$ ), skill development (e.g., reading research articles, oral presentation skills, and collaborative ability; 21.60\%), knowledge of diagnostic tools and treatment approaches specific to ASD (20.99\%), and knowledge of ASD $(19.75 \%)$. Goals that did not relate to one of the above themes were classified as "other."

Knowledge and Confidence. Composite ratings of students' knowledge and confidence in applying each course topic area, materials, and supports were calculated. There were no significant 
cohort differences or significant differences between graduate and undergraduate students on the composite measures. Paired sample $t$-tests revealed that undergraduate students rated their content knowledge significantly higher than their perceived confidence to apply information both during the fall and spring semesters, $t(18)=6.91$ and $t(18)=5.92$, both $p \mathrm{~s}<.001$. However, MA-SLP students' perceived knowledge and confidence were not significantly different for the fall or spring semesters, both $p$ s $>.05$.

Skills Obtained. Undergraduate students' perceptions of additional skills obtained (e.g., critical analysis, oral presentation skills) from the beginning to the end of each semester were significantly different for the fall as well as spring semesters, with students rating their skills at the end of the semester higher than their skills at the beginning of the semester, $t(18)=-7.16$ and $t(18)=-8.84$, both $p \mathrm{~s}<.001$. MA-SLP students also indicated a significant increase in their skills from the beginning to end of the fall and spring semesters, $t(7)=-3.97$ and $t(7)=-4.77$, both $p s<.01$. See Table 3 for a summary of students' perceptions of knowledge, confidence, and skills.

Student Assessment of Experience. At the end of each semester, students were asked to describe what they liked most about the training experience. Across both cohorts of MA-SLP and undergraduate students, five themes emerged. Percentage of total statements for each major theme are reported in rank order. Students valued the hands-on experience and opportunities related to creating evidence-based materials $(27.7 \%)$, collaborating with each other (18.24\%), learning how to effectively read and present information from research articles (15.5\%), learning from guest speakers (14.19\%), and information learned in courses and application of that material (13.03\%). Other themes that emerged included benefits associated with the small class size (9.46\%) and opportunities related to MA-SLP student mentorship of the undergraduates in the program $(2.70 \%)$.

Table 3

Student Self-Ratings of Knowledge, Confidence, and Skills by Semester

\begin{tabular}{|c|c|c|c|c|}
\hline \multirow[b]{2}{*}{ Parameter } & \multicolumn{2}{|c|}{ Undergraduates } & \multicolumn{2}{|c|}{ MA-SLP Students } \\
\hline & $\begin{array}{c}\text { Fall } \\
M \text { (SD) }\end{array}$ & $\begin{array}{c}\text { Spring } \\
M(\mathrm{SD})\end{array}$ & $\begin{array}{c}\text { Fall } \\
M(\mathrm{SD})\end{array}$ & $\begin{array}{c}\text { Spring } \\
M(\mathrm{SD})\end{array}$ \\
\hline Knowledge & $4.54(.29)$ & $4.36(.32)$ & $4.41(.43)$ & $4.34(.46)$ \\
\hline Confidence & $4.24(.37)$ & $4.10(.39)$ & $4.37(.52)$ & $4.22(.46)$ \\
\hline Beginning Skills & $3.53(.74)$ & $3.53(.75)$ & $3.87(.83)$ & $4.05(.45)$ \\
\hline End Skills & $4.63(.28)$ & $4.61(.35)$ & $4.52(.44)$ & $4.82(.27)$ \\
\hline
\end{tabular}

Note. Composite scores for knowledge, confidence, and skills were compared within the groups of undergraduate students and graduate students by semester. $M=$ mean; SD = standard deviation.

\section{Discussion}

This training and outreach program established for families who have children with ASD has significant educational, clinical, and philanthropic value. From the student perspective, there was an opportunity to learn about ASD, create materials to support communication, set realistic goals, and gain important hands-on experience. From the family perspective, our program provided support in an underserved community, valued and prioritized caregiver input in the creation of 
supports and materials, and provided caregivers with instructions and resources for use of the materials at home.

Learning Through Community Outreach. Both the families and the students benefited from the training and outreach program. First, families were provided with support in an underserved, rural community in the state. According to the most recent Ohio Poverty Report (Ohio Development Services Agency, 2017), Athens county has the highest reported poverty rate in the state at $33 \%$. Other surrounding rural counties have reported poverty rates upwards of $20 \%$. Through this program, families were provided with materials that otherwise may not have been executed independently or by those involved in their child's plan of care. Resources that we have regular access to, including computer software programs for generating picture icons and high quality printing and laminating materials, were not readily available to participating families. The high level of caregiver satisfaction with the provided materials as well as their interaction with students and staff team members provides support for programs of this type. Further, the caregivers' input was an integral part of the assessment process and helped students to be responsive in personalizing materials they developed and created for families' at-home use.

The other primary beneficiaries of this program were the university students who participated. Through the experience, the students not only learned about ASD, but they also connected the material they learned to the individualized materials they created to fit families' specific needs. Students engaged in a novel, hands-on experience by creating materials to support daily communication needs of participating children and their families. Though the two students from music therapy and the graduate students had some prior clinical experience, the opportunity to provide assistance to families in the community was a unique opportunity for all involved. These are exactly the types of professional preparation options that afford students the opportunities to apply their content knowledge and skills developed in the courses and positively impact the families who participated.

Developing Students' Skill Sets. All undergraduate and graduate students learned how to set realistic, measurable goals. The fact that $97 \%$ of goals set over the course of the training program were met or partially met is a reflection of the quality of students' abilities to write measurable goals. Across all students, more than $90 \%$ of students' goals were focused on creating materials and working with families, skill development, knowledge of diagnostic tools and treatment approaches specific to ASD, and knowledge of ASD. Though we anticipated that students would want to increase their knowledge of ASD as well as assessment and treatment protocols, we were pleased that a good proportion of students' goals centered on improving their own personal skill sets related to facility of reading research articles and delivering oral presentations. MA-SLP students learned more about the fine art of mentoring and assumed a leadership role throughout the experience; they were a point of connection between the primary and co-investigators and helped to facilitate the completion of the materials for the families in an organized and timely fashion (see Wright et al., in press).

Knowledge, Confidence and Skills Learned. There was a significant difference in undergraduate students' reported knowledge of topics covered in the course and their confidence in their ability to apply that information. This difference is not necessarily surprising, given that the majority of participants had minimal or no experience in treating children with ASD. As suggested by the 
findings of other investigations (e.g., Plumb \& Plexico, 2013), experience plays a significant role in increasing SLPs' confidence in working with children with ASD. The training program was designed to provide the students with a strong foundational knowledge of ASD that would ideally carry over into their current and future clinical experiences in working with that population. As noted in previous research (Freedman, 2014; Price, 2013), coursework specifically addressing ASD is uncommon at both the MA-SLP and undergraduate levels, making this program a unique opportunity for the students involved. Though there was a significant difference between the undergraduates' knowledge and confidence, it is important to note that their composite confidence scores still exceeded a 4 out of 5. Additionally, there was not a significant difference between MASLP students' reported knowledge of course content and their confidence in applying that information. It is quite possible that their role as a "mentor" and their graduate level status lead to a self-perception of having prior qualification for working with individuals with ASD and their families.

\section{Implications for Undergraduate and Graduate Training}

It is important to note features of our undergraduate and graduate programs that influenced our decision-making in the design and implementation of our training program. Students in our undergraduate program do not provide direct services in our clinic. The majority of their coursework focuses on speech, language, and hearing sciences with relatively few elective courses on disorders. Our six-semester MA-SLP program involves four consecutive semesters of didactic coursework (fall, spring, summer, fall) and university clinic experiences throughout the program. In addition, students have at least one outplacement for a single semester for a full day in a school, hospital, or skilled nursing facility. During the last two semesters (spring and summer of year two), the overwhelming majority of our students complete externships in a school and adult clinic facility, respectively. Programs contemplating adopting the model in the present study would need to consider the structure, timing, and sequence of coursework and experiences in their undergraduate and graduate programs and modify the training model to suit their needs.

In addition to logistics, future programs may not wish to focus solely on ASD. The model presented here can be adapted to suit a variety of families who have family members with disabilities beyond those with children who have ASD. As noted by Schwartz and Drager (2008) and others (Plumb \& Plexico, 2013), reports of limited knowledge on particular disorders are not limited to ASD. These knowledge limitations are not only an issue in our field, but related fields as well, including music therapy and education. The primary focus of our undergraduate major is on establishing foundational knowledge related to communication disorders, so the opportunity to explore specific disorders may be somewhat limited in undergraduate programs that offer many introductory courses and few didactic courses on communication disorders (e.g., language disorders and speech-sound disorders). Training programs such as these allow students to directly apply what they are learning in the classroom and help them to align their knowledge with best practices. Connecting classroom experiences to clinical settings is certainly one mechanism that can be used to strengthen students' knowledge and confidence in applying the material they learn in didactic coursework.

The findings here also highlight the importance of in-depth training experiences prior to entry into the workforce. None of the undergraduate students in CSD had any direct clinical experience with 
children with ASD, nor did the student from psychology. Though the two students from music therapy had engaged in clinical practice, their knowledge of ASD from an interprofessional perspective was still emerging. MA-SLP students CSD were in their first year of graduate school and still working on developing and honing their clinical skills and knowledge base of ASD. We were fortunate to have three students from outside of CSD participate in the training program during the second cohort. Several students mentioned the value of having students from other fields participate. The three students from other fields also noted the importance of interfacing with undergraduate students in the CSD major and how they planned to utilize and integrate the materials they learned to design (e.g., visual schedules) into their own therapy for clients with ASD.

Students' perspectives were broadened beyond interactions with their peers, faculty and staff affiliated with the program. Guest speakers from various fields including music therapy, social work, and occupational therapy visited the classes to share their field's role in working with children with ASD and their families. Each of these professionals also discussed the potential for interprofessional collaboration and how future SLPs and professionals from other disciplines could collaborate with them. Our findings revealed that more than $14 \%$ of the features of the training courses that students liked most involved learning from the guest speakers. Their lectures broadened students' understanding and alerted them that the best outcomes for children with ASD and their families could be achieved not only by having an awareness of other professionals' roles, but also by working together to optimize outcomes for the children and their families.

\section{Limitations and Future Directions}

The two cohorts in this study only included three students from majors outside of CSD. The recruitment of an equal balance of undergraduates from CSD and other related disciplines would enrich the content and quality of discussions surrounding autism. Though several students from education expressed an interest in participating in the training program, their practicum requirements during spring term precluded them from committing to the two semester requirement. As one can imagine, scheduling was somewhat of a challenge as coordinating time across students from multiple programs with different class, work and personal responsibilities required the students to adjust their schedules and coordinate with each other.

Future iterations of the training program will involve exploring the promise of other training models that last for a shorter timeframe (one semester) or seeking opportunities for outreach within pre-professional courses at the undergraduate level, graduate seminars, and student organizations. Given that guest speakers were popular among participants, a model with co-teaching or shared seminar formats across multiple disciplines is another future possibility. Additional course formats include creating online modules for lectures and adding modules on the creation of the evidencebased materials. Another future direction is to expand the outreach beyond families to other professionals who work with children with ASD, including SLPs and teachers in mainstream and special education classrooms. With respect to outreach to families, additional extensions include multiple follow-up sessions in person, as well as opportunities to modify materials or make new requests (i.e., 2-4 times over the course of a year).

\section{Conclusion}


Overall, we deem the first two years of this program a success. The needs of the intended beneficiaries of this program, the families and the students, were met. The quantitative and qualitative data support the extent to which this program addressed a clear need at our university and in our community. Though training programs that involve embedding community outreach require the facilitators to expend a great deal of time and effort, the payoff is well worth the energy. It is our hope that the work we have done with our students and in our community will spur further development and expansion of training programs that benefit as many stakeholders as possible.

\section{References}

American Speech-Language-Hearing Association. (n.d.) Autism [Practice Portal]. Retrieved June 21, 2017 from www.asha.org/Practice-Portal/Clinical-Topics/Autism/

American Speech-Language-Hearing Association. (2015). SLP healthcare survey 2015. Retrieved from http://www.asha.org/uploadedFiles/2017-SLP-Health-Care-Survey-Summary.pdf

American Speech-Language-Hearing Association. (2016). 2016 schools survey. Retrieved from http://www.asha.org/uploadedFiles/2016-Schools-Summary-Report.pdf

Auert, E. J., Trembath, D., Arciuli, J., \& Thomas, D. (2012). Parents' expectations, awareness, and experiences of accessing evidence-based speech-language pathology services for their children with autism. International Journal of Speech-Language Pathology, 14, 109-118. doi: 10.3109/17549507.2011.652673

Cascella, P. W. \& Colella, C. S. (2004) Knowledge of autism spectrum disorders among Connecticut school speech-language pathologists. Focus on Autism and Other Developmental Disabilities, 19, 245-252. doi: 10.1177/10883576040190040601

Donaldson, A. L. (2015). Pre-professional training for serving children with ASD: An apprenticeship model of supervision. Teacher Education and Special Education, 38, 5870. doi: 10.1177/0888406414566995

Dunn Buron, K., \& Curtis, M. (2012). The incredible 5-point scale: The significantly improved and expanded second edition. Shawnee Mission, KA: AAPC Publishing.

Finke, E., Drager, K. D. R., \& Serpentine, E. C., (2015). "It's not humanly possible to do everything": Perspectives on intervention decision-making processes of parents of children with autism spectrum disorders. Perspectives on Language Learning and Education, 22, 13-21. doi: 10.1044/lle22.1.13

Freedman, S. E. (2014). Knowledge of autism spectrum disorder among college students in healthcare disciplines. SIG 10 Perspectives on Issues in Higher Education, 17(1), 17-26.

Gadberry, A. L. (2011). A survey of the use of aided augmentative and alternative communication during music therapy sessions with persons with autism spectrum disorders. Journal of Music Therapy, 48(1), 74-89. doi: https://doi.org/10.1093/jmt/48.1.74

Gray, C. (2015). The new social story book. Arlington, TX: Future Horizons.

Howell, D. M., Wittman, P., \& Bundy, M. B. (2012). Interprofessional clinical education for occupational therapy and psychology students: A social skills training program for children with autism spectrum disorders. Journal of Interprofessional Care, 26, 49-55. doi: $10.3109 / 13561820.2011 .620186$

Jonsson, A., Kristoffersson, L., Ferm, U., \& Thunberg, G. (2011). The ComAlong communication boards: Parents' use and experiences of aided language stimulation. Augmentative and Alternative Communication, 27, 103-116. doi: 10.3109/07434618.2011.580780

Kleiman, L. I. (2003). Functional communication profile revised. Austin, TX: PRO-ED, Inc. 
Kovach, T. M. (2009). Augmentative and alternative communication profile. East Moline, IL: LinguiSystems, Inc.

Ohio Development Services Agency. (2017). The Ohio poverty report. [PDF file]. Retrieved from https://www.development.ohio.gov/files/research/p7005.pdf

Plumb, A. M. \& Plexico, L. W. (2013). Autism spectrum disorders: Experience, training, and confidence levels of school-based speech-language pathologists. Language, Speech \& Hearing Services in Schools, 44, 89-104. doi: 10.1044/0161-1461(2012/11-0105)

Price, J. R. (2013). Preservice knowledge and training in autism spectrum disorders. SIG 10 Perspectives on Issues in Higher Education, 16, 71-80.

Rao, S. M., \& Gagie, B. (2006). Learning through seeing and doing: Visual supports for children with autism. TEACHING Exceptional Children, 38, 26-33. doi: 10.1177/004005990603800604

Schlosser, R. W., Shane, H. C., Allen, A. A., Abramson, J., Laubscher, E., \& Dimery, K. (2016). Just-in-time supports in augmentative and alternative communication. Journal of Developmental and Physical Disabilities, 28, 177-193. doi: 10.1007/s10882-015-9452-2

Schwartz, H., \& Drager, K. D. (2008). Training and knowledge in autism among speech-language pathologists: A survey. Language, Speech, and Hearing Services in Schools, 39, 66-77. doi: 10.1044/0161-1461(2008/007)

Serpentine, E. C., Tarnai, B., Drager, K. D. R., \& Finke, E. H. (2011). Decision making of parents of children with autism spectrum disorder concerning augmentative and alternative communication in Hungary. Communication Disorders Quarterly, 32, 221231. doi: $10.1177 / 1525740109353938$

Vohra, R., Madhavan, S., Sambamoorthi, U., \& St. Peter, C. (2014). Access to services, quality of care, and family impact for children with autism, other developmental disabilities, and other mental health conditions. Autism, 18, 815-826. doi: 10.1177/1362361313512902

Williams, K. L., Schroeder, J. L., Carvalho, C., \& Cervantes, A. (2011). School personnel knowledge of autism: A pilot survey. The School Psychologist, 65, 7-14. doi: http://dx.doi.org/10.1037/e582172011-003

Wright, B. M, Kuykendall, K., Apsley, J., McCullough, N., Doerbaum, H., Fowler, M.,.. \& Benigno, J. P. (in press). Graduate student reflections on mentorship in a training and outreach program for families of children with autism spectrum disorder. Teaching and Learning in Communication Sciences and Disorders. 


\section{Appendix A}

Student Fall Survey

1. Are you a GA or undergraduate student?

2. List relevant prior coursework (e.g., Language Development) and direct experience working with children with Autism.

3. What did you like most about this course? List at least 3 specific aspects of the course that you enjoyed the most.

4. What did you like least about the course? List at least 3 specific suggestions for the future iterations of this course.

5. Revisit your goals from the beginning of the term. Did you meet, partially meet, or not meet each of the goals you set for yourself. Please explain your selection.

6. Please rate each area listed on two parameters: (1) knowledge gained and (2) confidence in applying that knowledge. ( $1=$ low; $5=$ high). Provide specific comments for each topic area.

Typical social communication and language development

Overview of autism spectrum disorders, stereotypes of autism and portrayals of ASDs in the media

Posting videos of children with ASD

Sounding the Alarm/Neurotypical

Overview of social cognition in children with ASD

Joint attention skills of children with ASD

Theory of mind abilities of children with ASD

Overview of executive function skills of children with ASD

Connections between EF and language in children with ASD

Relative strengths: children with ASD as visual learners

Relative strengths: routines

Case study analysis

Guest speakers: professionals who work with children with ASD

Functional Communication Profile

Introduction to augmentative and alternative communication

Introduction to apps and software: Autismate/Boardmaker

Creating a mini communication book

Picture Exchange Communication System

Social Thinking

Social Stories/YouTube examples and lecture

Visual schedules

Incredible 5-Point Scale

7. Additional Skills. Where applicable, please assess your confidence in the following skill areas at the beginning and end of the term. 
Reading and summarizing research articles

Written language skills

Critical thinking skills

Collaborative ability

Oral communication skills: presenting and leading article discussions

8. For Undergraduates only. Please rate the support of the GAs on the following assignments (1=not supportive at all; 5=strong support)

Presentation \#1

Presentation \#2

Final project

9. For GAs only. Please rate the following experiences ( $1=$ not beneficial; $5=$ very beneficial)

Constructing a mentoring statement

3-D printing

Meetings with faculty member and clinical supervisor 


\section{Appendix B}

Student Spring Survey

1. Are you a GA or undergraduate student?

2. List relevant prior coursework and direct experience working with children with Autism.

3. What did you like most about this course? List at least 3 specific aspects of the course that you enjoyed the most.

4. What did you like least about the course? List at least 3 specific suggestions for the future iterations of this course.

5. Revisit your goals from the beginning of the term. Did you meet, partially meet, or not meet each of the goals you set for yourself. Please explain your selection.

6. Please rate each area listed on two parameters: (1) knowledge gained and (2) confidence in applying that knowledge. ( $1=$ low; $5=$ high $)$. Provide specific comments for each topic area.

Introduction to current evidence-based approaches

Treatment in the schools: SCERTS and Ziggurat

Video modeling

Augmentative and Alternative Communication Profile

Mini communication books

Picture Exchange Communication System

Social Stories

The Incredible 5-Point Scale

Visual schedules

Caregivers of children with ASD

Children with ASD in the classroom setting

Adolescents and adults with ASD

Guest speaker(s): professionals who work with children with ASD

7. Additional Skills. Where applicable, please assess your confidence in the following skill areas at the beginning and end of the term.

Reading and summarizing research articles

Written language skills

Critical thinking skills

Collaborative ability

Oral communication skills: presenting and leading article discussions

8. For Undergraduates only. Please rate the support of the GAs on the following assignments ( $1=$ not supportive at all; $5=$ strong support)

Presenting research articles 
Creating materials and supports for families

9. For GAs only. Please rate the following experiences ( $1=$ not beneficial; $5=$ very beneficial)

Developing a mentoring philosophy

Interacting with families

Undergraduates' creation of materials for families

Meetings with faculty mentor and clinical supervisor 